\title{
Ataxia caused by mutations in the $\alpha$-tocopherol transfer protein gene
}

\author{
Fusako Usuki, Kei Maruyama
}

\begin{abstract}
A 48 year old woman with ataxia with vitamin E deficiency is described. Gene analysis identified two point mutations in exon 1 of the $\alpha$-tocopherol transfer protein ( $\alpha$-TTP) gene, one missense mutation and an upstream initiation codon mutation in the 5'-untranslated region (Kozak sequence). The latter mutation is the first one identified in the translation regulatory region. This mutation decreased the level of $\alpha$-TTP protein expression. The clinical features included uncommon urinary disturbance and deafness and relatively rare retinitis pigmentosa. Supplementary therapy increased her serum vitamin $E$ concentration to the normal range with mild improvement of the deep senses.

(F Neurol Neurosurg Psychiatry 2000;69:254-256)
\end{abstract}

Keywords: ataxia with vitamin E deficiency; $\alpha$-tocopherol transfer protein gene; Kozak sequence; translation

Ataxia with vitamin E deficiency (AVED) is an autosomal recessive neurodegenerative disease characterised clinically by Friedreich-like ataxia, decreased proprioceptive and vibratory sensations, dysarthria, and hyporeflexia, with or without retinitis pigmentosa. Since the $\alpha$-tocopherol transfer protein $(\alpha$-TTP) gene was first identified as the defective gene in this disease in $1995,{ }^{1} 16$ mutations in the $\alpha$-TTPgene have been reported. ${ }^{2-10} \mathrm{~A}$ defect in $\alpha$-TTP leads to a failure to incorporate $\alpha$-tocopherol into very low density lipoprotein (VLDL) secreted by the liver. This impairment results in the low serum concentration of vitamin E. In this paper we present a Japanese familial patient identified with new mutations in the $\alpha$-TTP gene. We analysed a novel mutation upstream of the initiation codon using an in vitro transfection system.

\section{Patient and methods} PATIENT

The patient was a 48 year old woman, sixth of six siblings of a consanguineous marriage. At the age of 9 , she became aware of unsteadiness on walking. At the age of 13, she began to have difficulty with discrete finger movement. Her speech became slow and a urinary disturbance developed by age 16 . At the age of 23 , visual loss developed suddenly. She was confined to a wheelchair by her late 20s. Hearing disturbance appeared at the age of 38, and progressed slowly. Three of her siblings had similar symptoms. Her oldest brother exhibited dysarthria, ataxia, and visual loss. He committed suicide at the age of 26 . Another brother and sister exhibited ataxia, dysarthria, visual loss, and arrhythmia. They are deceased.

On physical examination, she exhibited ataxia, visual and hearing disturbances, muscular atrophy of the limbs, decreased joint sensation, and absent vibratory sensation, gloves and stocking type sensory disturbances, absent deep tendon reflexes, bilateral Babinski's sign, slurred speech, urinary disturbance, and retinitis pigmentosa. Intellectual function was not disturbed. No bone deformities were recognised. Ophthalmoscopy showed bilateral typical changes of retinitis pigmentosa. Brain MRI showed some small T2 high intensity spots in the periventricular region and deep white matter but no cortical or cerebellar atrophy and no ventricular dilatation. An ECG showed supraventricular extrasystoles and possible anterior myocardial infarction. The serum vitamin E concentration was extremely low $(<0.10$ $\mathrm{mg} / \mathrm{dl}$; normal, 0.75-1.41). The serum concentration of $\beta$-lipoprotein was normal. Her mother and sister, neither of whom had similar symptoms, showed low to low normal vitamin E concentrations, 0.85 and $0.99 \mathrm{mg} / \mathrm{dl}$, respectively.

She was treated with $\alpha$-tocopheryl acetate ( 0.8 to $1 \mathrm{~g} /$ day) and her serum vitamin $\mathrm{E}$ concentration increased to $0.87 \mathrm{mg} / \mathrm{dl}$ after 10 months of treatment. Vibratory and joint position senses were moderately improved (from absent to 8-10 seconds), but major neurological signs have remained stable. However, she thought that her visual acuity had improved moderately 24 months after administration.

ANALYSIS OF THE MUTATION IN THE $\alpha$-TTP GENE Informed consent for $\alpha$-TTP gene analysis was obtained from the patient, but not from her mother and older sister. Genomic DNA was extracted from peripheral blood leucocytes. All five exons and flanking regions of the $\alpha$-TTP gene were amplified by the polymerase chain reaction (PCR), and subjected to direct nucleotide sequence analysis. The specific 
A

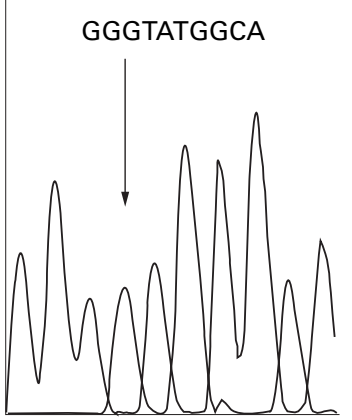

$\begin{array}{llll}\begin{array}{l}\text { Normal } \\ \text { sequence }\end{array} & \text { GGGC } & \frac{\text { ATG }}{\operatorname{Met}^{1}} & \frac{\text { GCA }}{\mathrm{Ala}^{2}} \\ \text { Patient } & \text { GGGT }^{*} & \frac{\text { ATG }}{\operatorname{Met}^{1}} & \frac{G C A}{\mathrm{Ala}^{2}}\end{array}$

C

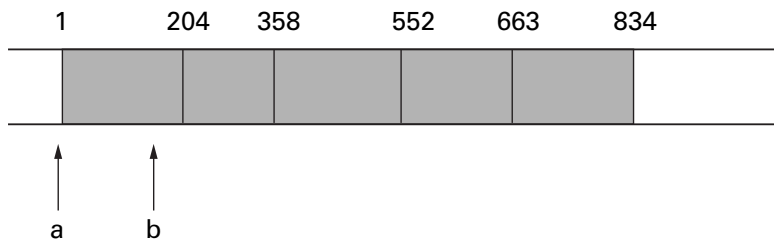

Figure 1 Identification of two point mutations in exon 1 of the a-TTP gene by sequencing analysis of $P C R$ products. $(A$ and $B$ ) The partial nucleotide sequences and partial amino acid sequences in DNA isolated from a normal subject and the patient. (A) The $C$ to $T$ transversion upper adjacent to the initiation codon in the 5'-untranslated region. (B) An A to $G$ transversion at nucleotide position 191 that replaces an aspartic acid codon (GAC) with a glycine $(G G C)$. (C) Diagram of human a-TTP $c D N A$. The arrows indicate the mutation positions.

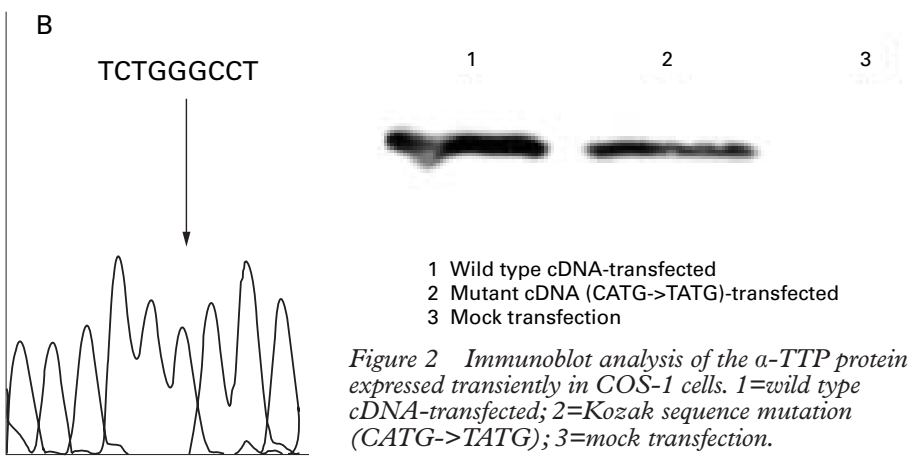

\section{CTG GAC CTG Results}

Direct nucleotide sequence analyses of the PCR products of five exons of the $\alpha$-TTP gene identified two point mutations in exon 1. The first change was a $\mathrm{C}$ to $\mathrm{T}$ transition upper adjacent to the initiation codon in the 5'untranslated region. The second was an $A$ to $G$ transition at nucleotide position 191, which changed an aspartic acid codon (GAC) to a glycine codon (GGC) (fig 1).

To examine whether the upstream initiation codon mutation affects the translation of the $\alpha$-TTP mRNA, we isolated the cDNA encoding human $\alpha$-TTP gene from a human liver cDNA library and constructed a mutant $\alpha$-TTP cDNA containing a $\mathrm{C}$ to $\mathrm{T}$ transition upper adjacent to the initiation codon. Western blot analysis of an extract of COS-1 cells transiently transfected with the wild type or mutant cDNA showed that the amount of $32 \mathrm{kDa}$ $\alpha$-TTP protein expressed by the mutant cDNA was smaller than that expressed by wild type cDNA (fig 2). NIH Image analysis showed that the ratio of the $\alpha$-TTP protein in mutant cDNA-transformants was about $53 \%$ that in wild type cDNA-transformants.

primer sets for four coding exons (exons 2-5) were synthesised and PCR was performed based on the results of previous studies. ${ }^{23}$ The specific primer sets for exon 1 were as follows; forward: CCAGGCTGGAGAGTGGTTGT GCGACGGG, reverse: GGACGGGGCGG GTGAGGTGCGCACTGCCGAGCGCCC. The PCR reaction was performed with LA-Taq (TAKARA, Japan) in 35 cycles of $95^{\circ} \mathrm{C}$ for 30 seconds, $60^{\circ} \mathrm{C}$ for 30 seconds, and $72^{\circ} \mathrm{C}$ for 1 minute.

A human liver 5'-stretch plus cDNA library (Clontech, Palo Alto, USA) and human liver cDNA library (TAKARA, Japan) were screened with a probe obtained by PCR for $\alpha$-TTP (nucleotide numbers from 19 to 826 ; Gene Bank accession number AF031323). The cDNA, including the whole coding region, was subcloned into a mammalian expression vector, pcDNA3 (Clontech, Palo Alto, USA). Mutant $\alpha$-TTP cDNA was obtained by site specific mutagenesis using a deoxyuridine template according to the standard method. COS cells transiently transfected with $\alpha$-TTP cDNA were harvested 48 hours after transfection. Immunoblot analysis was performed with a polyclonal rabbit anti- $\alpha$-TTP antibody raised against a synthetic peptide (CKSEDYLSSISESIQ-COOH) according to the C-terminal amino acid sequence of $\alpha$-TTP.

\section{Discussion}

We have presented a familial case with AVED caused by two novel point mutations in exon 1 of the $\alpha$-TTP gene. The mutations include one missense mutation and an upstream initiation codon mutation in the 5'-untranslated region. The first change is a replacement of an aspartic acid codon (GAC) with a glycine (GGC). This substitution seems to alter the conformation of the $\alpha$-TTP protein because glycine residues are the smallest uncharged amino acids. The second mutation region around the 5 ' end of a gene is assumed to be important to the regulation of the translation of the mRNA. ${ }^{11}$ The wild type sequence of this site, gcgggcATGgca, does not match the typical optimal context for the initiation of translation, gccaccATGg (Kozak sequence). However, the sequence found in this patient, ggcgggtATGgca, seems to differ further from the above Kozak sequence. In transient expression using COS cells, this mutation decreased the level of $\alpha$-TTP protein expression to about $53 \%$ that of normal cDNA. Since transcription activity is very high in COS cells, the translation of the mutated mRNA might be much less in vivo. It seems reasonable to expect that these mutations cause the defect in the vitamin E transporting activity in this patient. 
The patient showed a severe phenotype characterised by early onset neurological defects including ataxia, decrease in deep sensations, deafness, muscular atrophy, glove and stocking type sensory disturbances, slurred speech, urinary disturbance, and retinitis pigmentosa. Retinitis pigmentosa is often combined with this disease in Japan and has been reported to be associated with the $\mathrm{His}^{101} \mathrm{Gln}$ mutation of the $\alpha$-TTP gene. ${ }^{45}$ However, recently, the mutation of start codon of the $\alpha$-TTP gene has been reported to show retinitis pigmentosa. ${ }^{10}$ And in this study retinitis pigmentosa was associated with two point mutations in exon 1 of the $\alpha$-TTP gene. The clinical features included uncommon deafness and urinary disturbance besides relatively rare retinitis pigmentosa. ${ }^{510}$ As vitamin $\mathrm{E}$ is an important antioxidant, the disease process of AVED is predicted to be affected not only by genotype but also by environmental stresses, genetic background for other antioxidants, or dietary nutritional conditions. Her serum vitamin $\mathrm{E}$ concentration increased to the normal range after supplementation with $\alpha$-tocopheryl acetate. Treatment with $\alpha$-tocopheryl acetate has been reported to increase the concentration of $\alpha$-TTP protein in an in vitro expression system. ${ }^{6}$ Another report states that synthetic vitamin $\mathrm{E}$ need not be incorporated into the $\alpha$-TTP protein. ${ }^{12}$ The mechanism by which supplementation with synthetic $\alpha$-tocopheryl acetate results in a normal range of the patient's serum vitamin E concentration remains to be solved. So far, $\alpha$-TTP has been considered to express exclusively in the liver. However, recently, slight expression of $\alpha$-TTP in the brain, ${ }^{13}{ }^{14}$ spleen, ${ }^{13}$ lung, ${ }^{13}$ and kidney ${ }^{13}$ has been reported. In addition, the upregulation of $\alpha$-TTP has been reported in AVED, Parkinson's disease, Down's syndrome, and Alzheimer's disease. ${ }^{14} \alpha$-TTP may play a part in transporting $\alpha$-tocopherol intracellularly as well as in liver cells.

Further studies of the distribution and function of $\alpha$-TTP in various tissues will allow us to develop useful therapy for AVED and to help prevent disease progress in other neurodegenerative diseases in which oxidative stresses are suspected to play a part.

We thank Dr Takanori Yokota, Department of Neurology, Tokyo Medical and Dental University, for the gift of primers and helpful comments.

1 Ouahchi K, Arita M, Kayden $\mathrm{H}$, et al. Ataxia with isolated vitamin $\mathrm{E}$ deficiency is caused by mutations in the $\alpha$-tocopherol transfer protein. Nat Genet 1995;9:141-5.

2 Gotoda $\mathrm{T}$, Arita $\mathrm{M}$, Arai $\mathrm{H}$, et al. Adult-onset spinocerebellar dysfunction caused by a mutation in the gene for the $\alpha$-tocopherol transfer protein. $N$ Engl 7 Med 1995;333. 1313-8.

3 Hentati A, Deng H-X, Hung W-Y, et al. Human $\alpha$-tocopherol transfer protein: gene structure and mutations in familial vitamin E deficiency. Ann Neurol 1996;39: 295-300.

4 Yokota T, Shiojiri T, Gotoda T, et al. Friedreich-like ataxia with retinitis pigmentosa caused by the $\mathrm{His}^{101} \mathrm{Gln}$ mutation of the $\alpha$-tocopherol transfer protein gene. Ann Neurol 1997;41:826-31.

5 Shimohata $\mathrm{T}$, Date $\mathrm{H}$, Ishiguro $\mathrm{H}$, et al. Ataxia with isolated vitamin E deficiency and retinitis pigmentosa. Ann Neurol 1997;43:273.

6 Tamaru Y, Hirano M, Kusaka H, et al. $\alpha$-Tocopherol transfer protein gene: exon skipping of all transcripts causes ataxia. Neurology 1997;49:584-8.

7 Martinello F, Fardin P, Ottina M, et al. Supplemental therapy in isolated vitamin $\mathrm{E}$ deficiency improves the peripheral neuropathy and prevents the progression of ataxia. F Neurol Sci 1998;156:177-9.

8 Cavalier L, Ouahchi K, Kayden HJ, et al. Ataxia with isolated vitimin $\mathrm{E}$ deficiency: heterogeneity of mutations and phenotypic variability in a large number of families. Am f Hum Genet 1998;62:301-10.

9 Schuelke M, Mayatepek E, Inter M, et al. Treatment of ataxia in isolated vitamin $\mathrm{E}$ deficiency caused by $\alpha$-tocopherol transfer protein deficiency. F Pediatr 1999; 134:240-4.

10 Hoshino $\mathrm{M}$, Masuda N, Ito $\mathrm{Y}$, et al. Ataxia with isolated vitamin $\mathrm{E}$ deficiency: a Japanese family carrying a novel mutation in the $\alpha$-tocopherol transfer protein gene. Ann Neurol 1999;45:809-12.

11 Kozak M. Interpreting cDNA sequences: some insights Kozak M. Interpreting cDNA sequences: some insights
from studies on translation. Mamm Genome 1996;7:56274.

12 Traber MG, Ramakrishnan R, Kayden HJ. Human plasma vitamin $\mathrm{E}$ kinetics demonstrate rapid recycling of plasma RRR- $\alpha$-tocopherol. Proc Natl Acad Sci USA 1994;91: 10005-8.

13 Hosomi A, Goto $\mathrm{K}$, Kondo $\mathrm{H}$, et al. Localization of $\alpha$-tocopherol transfer protein in rat brain. Neurosci Lett 1998;13:159-62.

14 Copp RP, Wisniewski T, Hentati F, et al. Localization of $\alpha$-tocopherol transfer protein in the brains of patients with ataxia with vitamin E deficiency and other oxidative stress related neurodegenerative disorders. Brain Res 1999;822: $80-7$. 